\title{
Ambiguity and Communicative Strategy in Japanese Story Retelling
}

\author{
Mintarsih \\ Universitas Negeri Surabaya \\ Surabaya, Indonesia \\ Mintarsih@unesa.ac.id
}

\author{
Didik Nurhadi \\ Universitas Negeri Surabaya \\ Surabaya, Indonesia \\ didiknurhadi@unesa.ac.id
}

\begin{abstract}
The purpose of this study is to describe and explain the trigger of ambiguity factors in Japanese story retell toward 5 students in the third and fourth semesters. It also aims to find out the communicative strategy which is used during the communication. The data was gathered through semi-structured interviews using illustration pictures as elicit media, after that the conversation was being recorded and transcribed. The data analysis was transformational generative grammar. The results of the analysis show that the trigger of ambiguity factors was the aspect of language competence which is vocabulary mastery and grammar, the complexity level of sentence structures, and the cognitive aspects. Meanwhile, the communicative strategies were reduction strategy and achievement strategy. This study is beneficial to develop communicative competence in Japanese language teaching.
\end{abstract}

Keywords-ambiguity; ambiguity factors; communicative strategy; Japanese; communicative competence

\section{INTRODUCTION}

Ambiguity is a construction that leads to many interpretations in a sentence. Pangaribuan [1] said that a sentence can be considered as a good sentence (wellformedness) if it has the elements of simplicity, thrifty, and clarity. Ambiguity itself indicates communicative competence imperfection of learners, for example, learners' utterance in the story retell (1) Kono kono mizu wo eu... moraite, ie kara totemo nagai kedo, kore wa eu...eu... un undo eu karada no undo ga ii to omoimasu (eu ... accepts this this water, even though long from home, this matter eu ... eu ... sports eu spots good body I think. What is meant by the speaker in the sentence (1) unclear, because of mistakes unclear, because of mistakes unclear, because mistakes have happened syntactically (sentence structures), lexicon (word choice), and semantic (meaning)

According to Clark and Clark [2], speaking activity divided into two types, namely: planning and delivering the speech (planning and execution). In the speaking activity, first of all, the speakers plan (planning) what they want to deliver based on how the speakers want to change their mind (mental state) from the speech partner. The next step is the interlocutors realize speech plans in the form of delivering the speech (execution through segments, words, phrases, and sentences. Speech planning and execution follow the processes of discourse plannings, sentences, and constituents. After that, there are articulation programs and the last is articulation. The problems which commonly happened in this planing level are hard to be observed unless the speech has been explicitly uttered (spoken). Moreover, Clark and Clark [2] explained that planing one of the processes to choose, heuristic and a purpose to be actualized. The real concrete solution of the planning problems in the mind will appear in the form of mistakes and discourse corrections.

Ambiguities have probably happened because lack of language rules mastery by learners of the target language. Furthermore, the researcher assumed that ambiguities have happened because the participants have mastered either Indonesian or English besides the rules of Japanese in the cognitive system. In this study, ambiguities in participants' discourse were described from story retelling the activities if retelling a story in Japanese. Story retelling is one of the speaking skill parts which need to be mastered by Japanese language learners. Holsanova [3] explained how the flow of mind appears in a speech, for example when retelling an event step by step where everyone could choose different focus and image according to their experience, and then constructs it in a particular order. At a certain point, the speakers let some aspects while, on the other hand, emphasizes another aspect, then categorize it, and sum up their experience in more complicated and complex orders. This phenomenon shows that learners are creating a pattern in their mind and offering certain speech format to the listeners. Chafe (1994) in Holsanova [3] emphasized that consciousness develops to experiences as the perceptions and actions which involve emotions, opinions, behaviors, etc. Sometimes, perceptions, actions, and evaluations comprise introspection and metaconsciousness. Based on the result of the study, Holsanova [3] explained how at the same time participants drew a flock of birds and evaluated the situation which depicts on the picture, painted the quality of the soil, expressed the similarity by using a metaphor, and characterized the other pictures. The participants were not only expressed their ideas about the situations, events, and certain references but also evaluated them in various ways. Therefore, it can be understood that the participants were not only mentioned what depicted in the picture but also how the picture looked like based on their perspectives. In other words, participants expressed their attitudes toward the content, evaluated and gave a comment to the other aspects depend on the place where the event took place. 
When the story retelling went on, the participants attempted to reduce ambiguities by applying communicative strategies such as for example code switching or code-mixing in their speech. Corder [4]; Tarone [5] stated that communicative strategies are a measurable effort from the speakers when they face some problems in meaning-making the target language. This is happened due to the lack of mastery of linguistic rules in the target language and learners' language proficiency is inadequate enough to clarify the meaning of the speech.

Ambiguities and communicative strategies are interesting to be explored altogether due to 1) indications that Japanese language learners realize the ambiguities on their talks, and try to clarify through certain communicative strategies, and 2) the common causes of ambiguities and communicative strategies during the speech which is inadequate target language rules mastery.

\section{METHODS}

\section{A. Participants}

The participants in this study were five university students (two students on level four, and three students on level three) in Japanese Education study program in Surabaya.

\section{B. Research procedure}

The data collection was done by using documentary technique, free and involved technique, and data transcription technique. The researcher conducted a semi-structured interview using story pictures as elicitation media. The participants were asked to tell (story retelling) fairy tales (Indonesian folktale) while looking at the folktales' pictures namely Bawang Putih dan Bawang Merah or Timun Mas. The participants' speech was recorded, transcribed and then offline analyzed.

\section{Data Analysis}

The data analysis based on Miles and Huberman [6], i.e. data reduction, data presentation, data verification, and conclusion. The analysis was done trough re-examine the transcription of student speech to find out what factors cause ambiguities and what kind of communicative strategies being used. Then, the data was classified and described. Speech data analysis followed the rules of discourse analysis and the generative grammar rules of transformation.

\section{RESULTS AND DISCUSSION}

The result of the study showed the factors which cause ambiguities involved: (1) language ability aspects that are vocabulary mastery and grammar, (2) sentence structure complexity, and (3) cognitive aspects. Meanwhile, the communicative strategies used were in the area of (1) reduction strategy and (2) achievement strategy.

\section{A. Factors that cause ambiguity}

1) Language competence aspects, namely vocabulary mastery and grammar.
Ambiguities appeared in words, phrases, clauses, and sentence structures as in the examples below (1).

The sentence structure (1) used conjunction kedo (even though), te (because, then), as follows: (1) kono mizu wo moraite, ie kara totemo nagai kedo, kore wa karada no undo ga ii to omoimasu (accept this water, even though long from home, this is good for exercising the body, I think), meanwhile the sentence structures (1) are: (a) kono mizu wo morau, (b) ie kara totemo nagai, (c) kore wa undo ga ii to omou. Kalimat (1) is difficult to understand because ambiguities appear in sentence structure, phrases, and words. To parse the ambiguity in the sentence (1), syntactically and semantically component analysis was done as follows.

First, ambiguities in the word nagai and phrase mizu wo morau. Nagai (long) has semantic features (+long measurement, +time measurement, +distance measurement) because what meant in the sentence (1) is distance measurement (far) from the house to the place to get the water, the appropriate word in the context should be toui (far). The reason is nature the word toui contains semantic meaning distance (far) in the context of distance measurement, which is (-long measurement, -time measurement, +distance measurement). In the phrase mizu wo morau, participants translated it as taking the water, receiving/getting the water. In Japanese rulesm, the prase taking the water, receiving/getting the water in that sentence will be more suitable to the context if it uses the idiom mizu wo sukuu (taking the water). Even though the words nagai and toui are different in the same words category which is adjective ended by $\mathrm{i}$, it has different meanings semantically. As well as the phrase structure similarities in mizu wo morau and mizu wo sukuu that is $\mathrm{FN}+\mathrm{PO}+\mathrm{FV}$, but the meaning is different.

Second, ambiguity appeared in te conjunction (because, then). The acceptable subordinate phrase conjunction in sentence (1) is the conjunction which means 'for' such as tame $n i$ because the relation between two subordinate phrases in sentence (1) is the destination, while conjunction te means 'because' which shows cause and effect, or it means 'then' which shows the sequence of events. Ambiguities also shows in the use of kedo conjunction (even though, although, but). Conjunction kedo has many meanings (polysemy), what was being meant to be delivered by the participants through the use of conjunction kedo was not clear because they suddenly did an evaluation to the situation faced by the character of Bawang Putih by saying kore wa...to omou (this is... I think) after conjunction kedo. Nitta [7] said that conjunctions keredo, kedo, ga, are used in equivalent clauses contrass, besides contain comparison meaning, concession, or contrast, such as takarakuji maikai katteirukedo, chottomo ataranai (even though has bought lottery several times, none was accurate)

Third, the ambiguities refer to the standard rules of writing sentence structure in Japanese, kore followed by wa marker in a sentence (1) is the subject of the main clause. It is because $w a$ is the topic marker or the sentence subject which also refers to the type of Japanese sentence structure namely SOV. Therefore, a subject is put at the beginning of the sentence and verb (V) is put at the end of the sentence. Ambiguities in the use or word kore create cohesion between the upper clause 
and the main clause. The participants used the pointing word kore with referring to the subordinate clause which was kono mizu wo morau, ie kara totemo nagai. This was not in accordance with the rules to construct complex sentences. When the subject in the main clause and subordinate clause in the same complex sentence, the subject can be omitted into the second clause, or only appears once in the main clause or subordinate clause. The subject will have appeared if each clause has a different subject. The subject in the sentence (1) both in the subordinate clause and the main clause is Bawang Putih. Therefore, the use of kore wa as the subject in the main clause of the sentence (1) created ambiguities syntactically and semantically.

In another example of sentence data (2) is the error in constructing the verb sentaku shiyo made the meaning of the sentence ambiguity, therefore the cohesion and coherence among words and phrases on that utterance were weak. Sentence (2) has outer-structure "jyaa, hayaku kono shatsu wo sentaku shiyo" (Hey, go wash the clothes soon!), while the inner-structure in that sentence is shatsu wo sentaku shimasu (washing the clothes). According to Parera [8] explanation, sentence (2) included in a single transformation with the type of imperative transformation. Based on the sentence context, the utterance meaning in imperative that was when the stepmother asked Bawang Putih to wash the clothes but the participants used the word invitation verb sentaku shiyo (let's wash) instead of the imperative verb of suru that is shiro. As a result, the phrase turned into sentaku shiro (wash!). This error is a grammatical mistake that automatically causes the semantic difference.

The next ambiguity in the third sentence appeared in data three which are these sentences. (3a) Sono sakana wa Bawang putih wo tasukete, sono sentaku ga kirei ni natta (because the fish will help Bawang Putih, the laundry gets clean). (3b) Itsumo kakurete, Bawang putih wa mo sentaku ga owatta, ie de kaerimasu (always hiding, Bawang Putih finished washing, go home). (3c) Sono sakana wo mite, Bawang merah wa sono sakana wa kaette moraimashita (seeing that fish, Bawang Merah accepts go home (?) that fish).

Based on Suhardi [9], sentences in that paragraph is transformation sentence combined type of alignment (serial) and the relation which shows time sequence. Sentence (3a) is a compound-complex sentence with subordinative relations, meanwhile (3b) and (3c) are a compound-complex sentence with coordinative relations. The meaning ambiguity is shown in the phrase itsumo kakurete (always hiding) in the sentence (3b). If we refer to the sentences in the previous paragraph, Bawang Merah was the one who was hiding. The participants supposed to bring back Bawang Merah as the subject of preparator because in the sentence (3a) the subject of preparator is sono sakana, and Bawang putih in the main clause of the sentence (3b). Therefore, the omission of Bawang Merah as the subject in the subordinate clause of the sentence (3b) made the phrase itsumo kakurete incoherence compared to the previous sentence, sentence (3a), and the previous sentence, sentence $(3 c)$. Based on the sequence of time, does the phrase itsumo kakurete refer to the previous sentence context which is hiding to see the god of fish to help
Bawang Putih or actually at the next sentence that is hiding to wait Bawang Putih return home and catch the fish?

The relation among those sentences was analyzed through the inner structure of each sentence as follows.
a. Sakana wa Bawang putih wo tasukeru
b. Sentaku ga kireida
c. Bawang merah wa kakusu
d. Bawang putih wa sentaku ga owaru
e. Bawang putih wa ie e kaeru
f. Bawang merah wa sono sakana wo miru
g. Bawang merah wa sono sakana wo morau
h. Bawang merah wa kaeru

Based on the transformational analysis process (Tproses) in sentences (3a-3c), it can be found some transformation rules, i.e.:

a. Changing the tasukeru verb into the conjunction verb te to be tasukete

b. Converting kireida adjectives to kireini + verbs

c. Completing the phrase bawang merah in a sentence (3b) is as follows (Bawang merah wa) itsumo kakurete

d. Changing transitive verbs kakusu into intuitive kakureru

e. Changing intransitive verbs kakureru into te form connective verbs to kakurete

f. Focusing/emphasizing by adding itsumo adverbs to the introitive verb kakureru to the phrase itsumo kakurete because the participants wanted to emphasize the phrase kakurete (hiding) that hiding continues over a long period of time

g. Focusing by permitting the phrase itsumo kakurete to the beginning of the sentence (3b)

h. Eliminating the conjunction made (up to) on the phrase ka-tta-made as the mark of activity limit, because participants made a focus transformation in the form of permutations on the phrase itsumo kakureru

i. Changing the word owaru on the conjunction verb ta into owatta

j. Changing the structure of the phrase mottekaerimashita into kaette moraimashita.

Based on the inner-structure analysis, ambiguities in sentences 3a-3b can be clarified in the following explanation: (1) the proper use of adverbs for kakurete phrases is not itsumo but zutto (continuity), because zutto is more suitable to explain that an action is done on and on in long period of time, (2) itsumo kakurete phrase (always hiding) refers to the hiding activity during Bawang putih washed the laundry until she was done and returned home. Bawang merah hid to peek the God of the fish's magic to help Bawang putih, and caught the magic fish after Bawang putih returned home, (3) the use of verb mitedan kaette moraimashita in the sentence (3b) is incorrect, not because of sakana o mite (see the fish) but the idiom sakana o tsutte (catch the fish), and the phrase kaette 
moraimashita (accept home (?)) should be motte kaerimashita (bring the fish home).

\section{2) Sentence structure complexity}

Sentence complexity is one of the factors that create participants' ambiguity during the story retell. Ambiguity and polysemy in conjunction, main and subordinate clause coherence, verb changes, and others make complex sentence mastery complicated, for example, word and phrase ambiguities, and sentences in the data sentence (1) and (3a-c). Complex sentences can be ambiguity in participants' speech because there is no subject, object, a sequence of events, and so on

\section{3) Cognitive aspects}

Cognitive aspects refer to the statement by Clark and Clark [2]; Chafe and Holsanova [3], related to planning and delivering the speech, thought flow, and the statement that consciousness in mind involve emotion, opinion, perception, and evaluation. Therefore, it can be said that speech is the actualization of thinking process complexity which motivated by various factors influencing each other. Related to that statement, the appearance of ambiguity in participants' speech is an interesting phenomenon. The long phase which happened when the participants wanted to continue the next sentence; the hesitation which marked by humming such as: euu, eto, $n g g . .$. and many more; there was words or phrase repetition; sudden change of sentences; there was code switching or code-mixing; there was combination of some overrated events, appears often -although not always- by the ambiguity appearance on participants speech. Typical features in spoken utterance such as hesitation identified by $e u$, repetition, causation, and participants assessments toward the events being told, such as in a clause to omou (I think) and karada no undo ga ii (this exercise is good for the body) is markers of cognitive activities which happened inside the participants. As has been stated by Clark and Clark [2] that speech mistakes happened because participants try to plan and produce utterance at the same time. This is marked by some tendencies, such as there is hesitation, correction, humming uhs, and the other tendencies which indicate that the participants are planning for the next talk in their cognitive system.

Ambiguities in speech show that what is wanted to be said is not always in line with what is being taught. Experiences and perceptions appear at the same time in bilingual and multilingual cognition. Speech plans in bilingual and multilingual are more complex because they involve more than one language which takes a role to produce the utterance. This statement is based on the research conclusion by Green (1986) in Cenoz [10] that bilinguals do not switch certain languages by on-off one language when they use another language, but it is because there is a different level of activation in those languages. The strongest activation level appears when a language is "chosen" and controls utterances. A language can be said "active" when the language plays a role in the ongoing speech process but it has no access to the speech channel. This happens because the language is in the "active" level and parallel with the "chosen" language. On the other hand, a language that can be said "ignored/not active" means it is in the lowest level of activation. Green underlies a statement of interaction between various languages in bilingual cognition. The interaction depends on those language activation levels with the "chosen" language.

\section{B. Communicative strategy}

Faerch and Kasper (1983) in Rosyidah [11] explained kinds of communicative strategies, those are: 1) reduction strategy which consists of formal and functional, 2) achievement strategy which consists of (a) compensation strategy (code switching, interlingual-transfer strategy, intralingual, cooperation, and non-linguistic), and (b) searching strategy (waiting until the needed item appears, using semantic fields, using another language to translate to the target language). Those communicative strategies are identified as being used by the participants during the story retell. Participants used various communicative strategies spontaneously in their speech, such as in the examples below.

1) Formal variety of reduction strategies, (4) sorekara kyojin ni negai ga arundesu to iu to iimashita (then said to the giant that I have a wish). Participants changed to iu with to iimashita, because they understand more about renyokei (verb formation with masu)

Functional variety, such as (5) aru hi saki no kyojin ga kimasu eu baasan ga kowakute, Timun mas o ... Timun mas ga disembunyikan... Timun mas san ga obaasan no ushiro ni imasu (once upon a time, the giant came eu grandmother scared and then Timun mas ... Timun mas was hidden... Timun mas behind the grandmother). Participants reduced actional because they could not deliver their speech in Japanese. The communicative strategy which was used was transfer speech with the subject of perpetrators kyojin ga (a giant) to the speech with the subject of perpetrators baasan ga (grandmother), and then because one of them forgot the word 'disembunyikan' in Japanese, the participant shift again to speech with the subject of the perpetrator Timun mas san ga (miss Timun mas).

2) Achievement strategy is a compensation strategy in the form of switch code, such as (6) mbok Srini ndak punya anak perempuan tinggal di hutan sendirian. Aru hi sono baasan ga kyujin ni aimashita (mbok Srini did not have daughters and live alone in the forest. One day, grandmother met the giant). The participant used Indonesian in the previous sentence, after that switch it to Japanese in the next sentence.

The use of various communicative strategy at the same time in the same utterance, namely: compensation strategy in the form of interlingual-transfer strategy, intralingual, and searching strategy in the use other language and translate it to the target language, such as (7) That beast mau mengabulkan permintaan mbok Srini with one condition, if she is in six years old that little girl should be diberikan kepada raksasa. Mbok Srini menyanggupi saran tersebut and then that beast give her a little a little thing like that mentimun ajaib for be planted by mbok Srini. Sono Biisto wa, "hai, wakaru yo, kore, kakambe no ichio agemasuyo". Sono kakambe wa, eto... plan... what is that... kalau ditanam akan keluar bijinya, akan keluar pohonnya. "a so desu ne, arigato gozaimasu”, after 
that, mbok Srini wa "wakarimashita", ato de ato de mbok Srini wa sono mono kara sono mono wo planting, mmenanam. (The giant wanted to grant mbok Srini wish in one condition if she turns six years old, she has to be given to the giant. Mbok Srini agreed and then the giant gave her small stuff like a magic cucumber to be planted by Mbok Srini. The giant said, "yes, I understand, this, for now, I give you this golden cucumber seeds, okay”. The cucumber seeds, ehmm... plan ... what is it ... if planted the seeds will come out, the trees will come out. "O, I see, thank you", after that, Mbok Srini said, "I understand”, after that after that mbok Srini from that stuff, planted the thing, planting).

Next is a compensation strategy in the form of cooperation. Participant A asked for help to participant B because A forgot to translate the word 'dirty' in Japanese, and then B let A knew, as follows (8) A: "soshite, kono...kotor hehe...”. (A: then, this ... dirty... hehe...). B: "kitanai” (dirty). A: "kitanai shatsu wa..." (dirty clothes...).

Compensation strategy in the form of nonlinguistic strategy, such as (9) dum dum dum ookina footstep o kikoemasu (dum dum dum great footsteps were heard). A participant used the sound dum dum dum to imagine the coming of the giant.

Searching strategy is in the form of waiting strategy until needed items appear, as follows (10) sono baasan wa kyojin ni jibun no itu problem eu ...itte, e...sono mondai o itte, kyojin ga kyuri kyuri no seed kyuri no eu sono kyojin ga baasan kyuri no seed o ageru agete, sono seed o plant suru plant shite sodatemasu (That grandmother to the giant her problem eu ... said, e ... say that problem, the giant cucumber seeds cucumber eu the giant grandmother cucumber seeds give and then give, plant planting take care of that seeds). The participant faced difficulties translated the word 'problem' to Japanese, after experiencing a pause for some time finally the participant able to translate it. However, it different from the word "seed". In the searching process of translating the word 'planting', the participant used English until the participant finally found the word sodatemasu (take care).

Searching strategy is in the form of semantic use strategies, as follows (11) minna wa kono kamigata wa eu...ichiban kanpekina kamigata o itta (they said hairstyle eu ... good hairstyle). The word kanpeki has a similar meaning to ii, yoi, subarashii, rippana (vocabularies which express something good, beautiful, magnificent and superb.

\section{CONCLUSION}

Ambiguity structures and word, phrase and sentence meaning is expected to have no cohesion or coherence in the participants' speech. Ambiguities that were found in participants' story retelling happened because of a lack of mastery of the rules in the target language, sentence structure complexity level in the target language, and cognitive aspects in participants' cognitive systems. Communicative strategies were done consciously and constantly as well as a varied variety of strategies in the reduction strategy and search strategy. There were differences indicated in communicative strategy which were used by the participants, such as students in level 3 were more often used code switching, meanwhile, students in level 4 tended to mix the code. This study has not finished explored deeper into both ambiguity aspects and participants' communicative strategies. For further studies, it is suggested to conduct research which focuses on the relation of linguistic competence and students' communicative strategy competence.

\section{REFERENCES}

[1] T. Pangaribuan, Paradigma Bahasa. Yogyakarta: Graha Ilmu, 2008.

[2] H.H Clark dan V.E. Clark, Psychology and Language: An Introduction to Psycholinguistics. USA: Harcout Brace Jovanovich, 1977.

[3] J. Holsanova, Discourse, Vision, and Cognition: Human Cognitive Processing. John Benjamin Publishing Company, 2008.

[4] S.P. Corder, "Strategies of Communication" dalam C. Faerch \& G. Kasper (ed.), Strategies in Interlanguage Communication. London: Longman, 1983.

[5] E.E. Tarone, The Dynamic Interlanguage: Empirical Studies in Second Language Variation. US: Springer, 1989.

[6] B.M. Miles, dan M. Huberman, Qualitative Data Analysis: An Expanded Sourcebook 2nd Edition. Sage Publications, Inc. 1994.

[7] Y. Nitta, Gendai Nihongo Bunpo 6: dai 11 bu Fukubun. Tokyo: Kurushio Shuppan, 2008.

[8] J.D. Parera, Dasar-Dasar Analisis Sintaktis. Jakarta: Erlangga, 2009.

[9] Suhardi. Dasar-Dasar Tata Bahasa Generatif Transformasional. Yogyakarta: UNY Press, 2017.

[10] J. Cenoz, B. Hufeisen, dan U. Jessner, Cross-linguistic Influence in Third Language Acquisition: Psychology Perspektif. Great Britain: Cromwell Press, Ltd. 2001.

[11] Rosyidah, "Strategi Komunikasi Pembelajar Bahasa Kedua” dalam Nurhadi (ed.), Dimensi-dimensi dalam Belajar Bahasa Kedua. Bandung: Sinar Baru Algensindo, pp. 84-93. 2010. 